\title{
Effects of Maintenance Strategies on the Life-cycle Performance and Cost of a Deteriorating RC Building with High-Seismic Hazard
}

\author{
Chien-Kuo Chiu ${ }^{1}$, Takafumi Noguchi ${ }^{2}$ and Manabu Kanematsu ${ }^{3}$
}

Received 8 October 2009, accepted 12 April 2010

\begin{abstract}
It is reasonable that when the service life in terms of structural safety of a deteriorating reinforced concrete (RC) building does not match the original target set by the user or owner, life-cycle maintenance strategies should be implemented. Although many systems for finding optimal maintenance strategies for RC buildings have been proposed recently, few have discussed the life prediction assessment for a deteriorating RC building and the effect assessment models for repair and retrofit. For these purposes, this paper was focused on the probabilistic assessment method of service life and life-cycle maintenance strategies.

In the service life assessment method proposed in this study, a reliability function of structural safety performance was built on the basis of the hazard rate or hazard function of a deterioration RC building during a rare earthquake. For selecting optimal maintenance strategies, probabilistic effect assessment models for repair/retrofit works (five repair/retrofit works were selected) that consider the recurrence of deterioration in repaired areas and the deterioration proceeding in unrepaired areas were developed in this research. These models reflect the effects of the maintenance strategies on the failure and spalling probability directly and can be used to estimate the life-cycle performance and cost of RC buildings.

Finally, on the basis of the effectiveness of the maintenance strategies in reducing the life-cycle cost or the minimal life-cycle cost, the optimal life-cycle maintenance strategy can also be identified by using this system; case studies were used to discuss the applicability of this system.
\end{abstract}

\section{Introduction}

Reinforced concrete (RC) structures or buildings deteriorate over time when exposed to corrosive environments. When the service life in terms of structural safety of a deteriorating reinforced concrete (RC) building does not match the original target set by its user or owner, life-cycle maintenance strategies should be implemented to prolong its life. Once the cause of corrosion has been determined, structural members, beams, or columns with reinforcing steel components corroded by carbonation or chloride ingress can be appropriately repaired or retrofitted. Although many researchers have proposed methods to minimize the life-cycle costs (LCC) (Mori and Ellingwood 1994; Frangopol et al. 1997; Val et al. 2005; Chiu et al. 2008; Kanematsu and Noguchi 2001), few have developed service life assessment methods that can be used to ascertain whether maintenance activities are needed, and determine the optimal life-cycle maintenance strategies for RC structures located in corrosive

\footnotetext{
${ }^{1}$ Assistant Professor, Dept. of Construction Engineering, National Taiwan University of Science and Technology, Taiwan.

E-mail:ckchiu@mail.ntust.edu.tw

${ }^{2}$ Associate Professor, Dept. of Architecture, The University of Tokyo, Japan.

${ }^{3}$ Associate Professor, Dept. of Architecture, Tokyo University of Science, Japan.
}

environments with high seismic hazard. For these purposes, there is a need for a system that can be used to assess the service life of an RC building in terms of its structural safety and to determine its optimal life-cycle maintenance strategies based on mitigation effectiveness in the LCC, which includes the risk of deterioration.

In the service life assessment method proposed in this study, a reliability function of structural safety performance was built on the basis of the hazard rate or hazard function of a deteriorating $\mathrm{RC}$ building during a rare earthquake. Assessment models for structural and serviceability performance of a corroded RC member have already been proposed by Chiu et al. (2008). This research focused on the performance of a corroded RC building and the effect assessment models for the repair or retrofit works. In addition, if more accurate assessment models for structural and serviceability performance of a corroded $\mathrm{RC}$ building than the models adopted herein are available, they can be introduced into this system for improving the estimation for the deterioration risk.

In order to identify appropriate life-cycle maintenance strategies for RC structures, it is necessary to specify the practical repair or retrofit works that can be applied. The selected works significantly affect the lifetime performance of the structures. In this study, the mitigation effectiveness of five repair or retrofit works was investigated; these works were chosen on the basis of investigations performed by other researchers and repair or retrofit companies. After repair or retrofit is conducted, 
the repaired or retrofitted area generally regains its initial condition instead of deteriorating further, and the durability of the area generally improves. However, the deterioration rates of unrepaired areas and repaired areas were found to be different (Sancharoen et al. 2008). Therefore, we developed probabilistic effect assessment models for the five repair or retrofit works selected in this study. In other words, we modeled the effects of the maintenance strategies on failure and spalling probability directly instead of reanalyzing deterioration by using the finite difference method (FDM), while taking into consideration the modified structural state created by the implementation of the maintenance strategies. This improves the computing efficiency of the system and enables the identification of an optimal life-cycle maintenance strategy. In addition to the deterioration proceeding from the unrepaired areas, the reoccurrence of deterioration in the repaired areas is also considered in the models.

Besides the probabilistic effect assessment models for the repair or retrofit works, this paper discusses cost evaluation methods for repair or retrofit works conducted on the basis of the degree of deterioration, which is defined by the spalling probability. Finally, by utilizing the mitigation effectiveness for the maintenance strategies in the LCC including the deterioration risk, which is defined as the reduction rate in the LCC or the minimal LCC pertaining to the maintenance strategy, the optimal life-cycle maintenance strategy can be determined. Case studies were used to evaluate the effectiveness of this system.

\section{Evaluation models of deterioration}

The deterioration of an RC building is mainly induced by chloride ingress or carbonation, which in turn leads to corrosion of the reinforced steel. Deterioration by carbonation was discussed in past research (i.e. Chiu et al. 2008). In this study, we have focused on chloride ingress (Fig. 1) and the analysis procedure introduced herein could be used to simulate other types of deterioration of $\mathrm{RC}$ buildings.

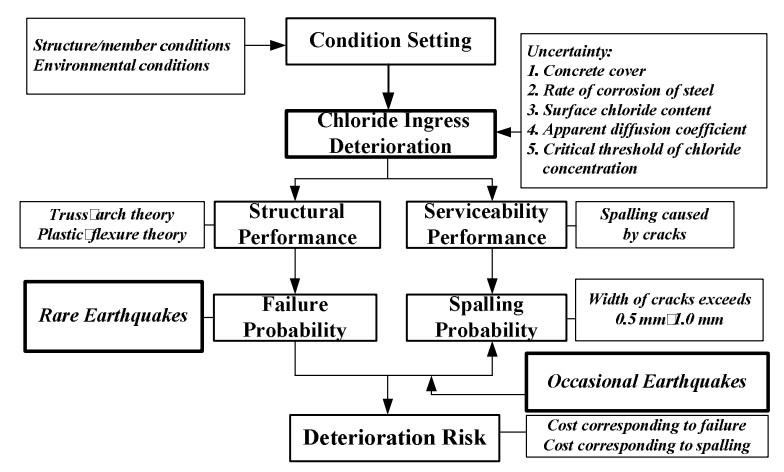

Fig. 1 Flowchart depicting the manner in which deterioration risk induced by chloride ingress is evaluated.
The chloride ingress deterioration model proposed in the design guidelines (AIJ 2004) for estimating the structural capacity of an RC member was used to evaluate the deterioration risk. Moreover, the corrosion of reinforcing steel due to chloride ingress was divided into four stages (initiation stage, propagation stage, acceleration stage and deterioration stage) and modeled accordingly following findings from previous studies (JCI 2004). The equations used in this study have been verified by many previous experiments; therefore, any uncertainty in the results is caused only by material deterioration and variation in the construction quality.

\subsection{Initiation stage}

This stage is defined as the time period required for corrosion to begin. Numerous studies have found that the ingress of chlorides through concrete is best represented by a diffusion process if the concrete is assumed to be relatively moist. In this study, we have assumed that the surface chloride concentration does not increase with time. Equation 1, which is based on Fick's second law, was used to estimate the chloride content $C l(\mathrm{x}, \mathrm{t})$ at the surface of the reinforcing steel:

$$
\begin{aligned}
& C l=\left(C_{o}-C_{\text {init }}\right)\left(1-\operatorname{erf}\left(\frac{x}{2 \sqrt{D_{p} t}}\right)\right)+C_{\text {init }} \\
& \log D_{P}=-3.9(W / C)^{2}+7.2(W / C)-2.5
\end{aligned}
$$

where $C_{o}, C_{\text {init }}, W / C, D_{p}$, erf, $x$, and $t$ are the surface chloride content $\left(\mathrm{kg} / \mathrm{m}^{3}\right)$, initial chloride content in concrete $\left(\mathrm{kg} / \mathrm{m}^{3}\right)$, water-cement ratio, apparent diffusion coefficient $\left(\mathrm{cm}^{2} /\right.$ year), error function, depth of concrete cover $(\mathrm{cm})$, and time (years) respectively.

Based on the results of previous studies (i.e. Kato and Uomoto 2005), we have assumed that corrosion is initiated when the chloride concentration of the surface of the reinforcing steel attains a critical threshold value, which is a uniformly distributed random variable in the range $1.0-1.2 \mathrm{~kg} / \mathrm{m}^{3}$. In this study, we considered the uncertainties associated with the apparent diffusion coefficient, concrete cover, and surface chloride concentration induced by environmental or construction conditions; the probability of the initiation of corrosion in the outermost reinforcing steel layer was calculated using Monte Carlo simulation (refer to Fig. 2). In the simulation, corrosion is assumed to have occurred when the probability of corrosion initiation exceeds $10 \%$ at a level of confidence of $90 \%$ (failure probability: 10\%); this condition is consistent with the prediction of corrosion initiation specified in ASTM C876 1991. In probabilistic analysis, the apparent diffusion coefficient, concrete cover, and surface chloride concentration are treated as lognormal random variables, as shown in Table 1.

\subsection{Propagation, acceleration and deterioration stages}

The propagation stage is defined as the period from cor- 
rosion initiation to cracking initiation on the concrete surface and followed by the acceleration stage and the deterioration stage in turn. In the deterioration stage, the deterioration process progresses and the structural capacity of the members is degraded significantly. Based on a previously developed model (JCI 2004), the rate of corrosion in these three stages is assumed to be identical, and this rate (expressed in terms of percentage weight loss) is treated as a lognormal random variable with a mean, $V_{\text {corr, }}$ which can be estimated using Equation 3, and a coefficient of variation of $50 \%$ (Takahashi et al. 2005):

$$
V_{\text {corr }}=\frac{78}{\sqrt{x}}(0.578 C l+0.023(W / C)-1.52)
$$

\section{Structural and serviceability performances of a deteriorating RC building}

\subsection{Reduction in structural capacity induced by corrosion}

The reduction in the shear and flexural capacity of an $\mathrm{RC}$ member due to corrosion is considered for investigating the safety performance under earthquake conditions. In this study, we considered the two major causes of reduction in structural capacity due to corrosion. The first cause is the reduction of the yield stress of the reinforcing steel. In the case of general corrosion, the yield stress of reinforcing steel, $\sigma_{y}$ can be estimated as (JCI 1998):

$$
\sigma_{y}=\sigma_{y o}(1-2.17 r / 100)
$$

where $\sigma_{y o}$ and $r$ are the yield stress of the reinforcing steel before corrosion $\left(\mathrm{N} / \mathrm{mm}^{2}\right)$ and corrosion of steel expressed as percentage weight loss (\%) respectively.

The second cause is the reduction of the ultimate bond stress of the reinforcing steel and concrete, $\tau_{b u}$ and it can be estimated as (JCI 1998):

$$
\begin{aligned}
& \tau_{b u}=\tau_{b o} \exp (-0.0607 r) \\
& \tau_{b o}=\left(1.2+5 p_{w} b / d_{b}\right) \sqrt{\sigma_{B}}
\end{aligned}
$$

Table 1 Statistics of deterioration parameters.

\begin{tabular}{|c|c|c|}
\hline Uncertainty & Distribution & C.O.V \\
\hline Surface chloride content $\left(C_{\mathrm{o}}\right)$ & Lognormal & $10 \%$ \\
\hline Depth of concrete cover $(x)$ & Lognormal & $20 \%$ \\
\hline Apparent diffusion coefficient $\left(D_{\mathrm{p}}\right)$ & Lognormal & $30 \%$ \\
\hline $\begin{array}{c}\text { Critical threshold of chloride con- } \\
\text { centration }\left(C_{\text {limit }}\right)\end{array}$ & Uniform & $\begin{array}{c}1.0-1.2 \\
\mathrm{~kg} / \mathrm{m}^{3}\end{array}$ \\
\hline Corrosion rate $\left(V_{\text {corr }}\right)$ & Lognormal & $50 \%$ \\
\hline
\end{tabular}

Probability den-

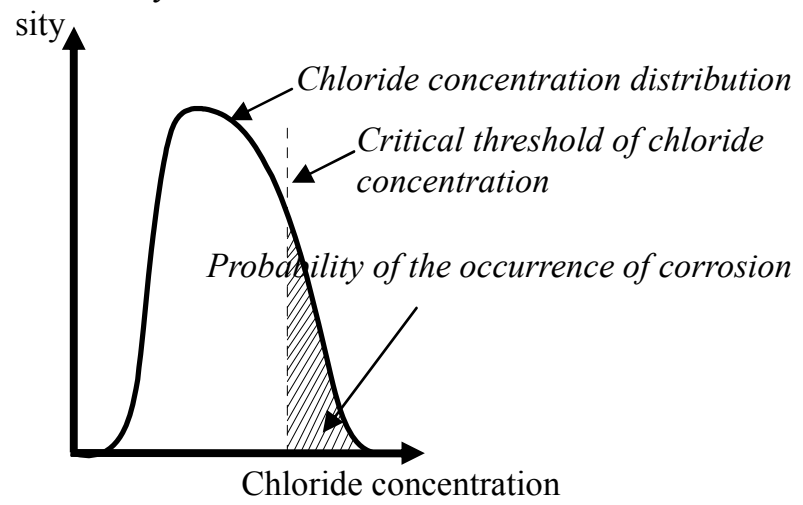

Fig. 2 Probability of the occurrence of corrosion in the outermost reinforcing steel layer.

where $\tau_{b o}, b, d_{b}, p_{w}$, and $\sigma_{B}$ are the ultimate bond stress of the reinforcing steel and concrete before corrosion $\left(\mathrm{N} / \mathrm{mm}^{2}\right)$, width of the member $(\mathrm{cm})$, diameter of the main bar $(\mathrm{cm})$, stirrup ratio, and compressive strength of concrete $\left(\mathrm{N} / \mathrm{mm}^{2}\right)$ respectively.

Based on the deterioration of materials stated above and using the proposed assessment models for determining the structural capacity of a corroded $\mathrm{RC}$ beam or column (Chiu et al. 2008), the shear capacity in the case of bonding failure, $V_{\text {bu }}$, the shear capacity in the case of stirrup yielding, $V_{\mathrm{u}}$, and the flexure capacity, $M_{\mathrm{u}}$, can be calculated respectively. However, the models have not been validated and calibrated by experiment. If more accurate models are available, they can be introduced into this system to improve the estimation for the structural capacity of a corroded RC beam or column.

\subsection{Structural performance and failure prob- ability}

The shear demand of a rare earthquake, $Q_{\mathrm{DS}}$ that might occur once in the lifetime of a structure (ISO3010, VISION2000), i.e. an earthquake that recurs every 500 years in Japan or Taiwan, is defined as the shear force generated by the earthquake and the vertical loading:

$$
Q_{D S}=Q_{L}+Q_{E}
$$

where $Q_{L}$ and $Q_{E}$ are the shear force generated by vertical loading $(\mathrm{N})$ and shear force $(\mathrm{N})$ generated by a rare earthquake that might occur once in the lifetime of the structure respectively.

The results of hazard analysis or seismic design codes can be used to determine the ground acceleration of a particular region subjected to a rare earthquake, allowing $Q_{\mathrm{E}}$ to be estimated using the pushover method.

Using the obtained values for structural capacity and shear demand of an RC member, as described in Section 3.1 , the shear performance index, $D_{\mathrm{V}}$ and flexural performance index, $D_{\mathrm{M}}$ can be calculated as follows: 


$$
\begin{aligned}
& D_{V}=\frac{\min \left(V_{b u}, V_{u}\right)}{Q_{D S}} \\
& D_{M}=\frac{2 M_{u} / L}{Q_{D S}}
\end{aligned}
$$

where $L$ is the clear span length of the member $(\mathrm{cm})$. A value of $D_{V} \leq 1.0$ implies shear failure. On the other hand, a value of $D_{M} \leq 1.0$ implies flexural failure.

Clearly, $D_{\mathrm{V}}$ and $D_{\mathrm{M}}$ decrease and approach the aforementioned limit (1.0) with the passage of time, as illustrated in Fig. 3. In this study, the rate of corrosion of reinforcing steel is considered a random variable, and Monte Carlo simulation is used to calculate the distributions of $D_{\mathrm{V}}$ and $D_{\mathrm{M}}$. Subsequently, the area of the distributions of $D_{\mathrm{V}}$ and $D_{\mathrm{M}}$ under the limit value can be evaluated and defined in terms of the shear failure probability, $P_{\mathrm{V}}$ and flexure failure probability, $P_{\mathrm{M}}$ respectively. In addition, the maximum of these two probabilities in each specified time is defined as the failure probability of the RC member.

In general, based on the failure probability of each column and beam in a building and its failure criterion, the failure probability of a building can be calculated accurately. However, it is difficult to determine the failure criterion of a building when the appropriate methods that can be used to assess the deformation performance of a corroded RC member, e.g. ductility, has yet to be resolved. Therefore, we estimated the probability of failure of a given floor using the weighted average method. As the axial-force capacity of a column reflects its significance in the stability of the adjoining floor, the ratio of the axial-force capacity of each column to the sum of the axial-force capacities of all the columns on the floor can be used instead of the axial-force capacity in the weighted average method, as shown in Equation 10 :

$$
P^{j}=\sum_{i=1}^{N}\left[\left(P_{V i}^{j}+P_{M i}^{j}\right) \times Q_{i}^{j}\right] / \sum_{i=1}^{N} Q_{i}^{j}
$$

where $P^{j}, P_{V i}^{j}, P_{M i}^{j}, Q_{i}^{j}, N$ are the failure probability of the $j^{\text {th }}$ floor, the shear failure probability of the $i^{\text {th }}$ column on the $j^{\text {th }}$ floor, the flexure failure probability of the $i^{\text {th }}$ column on the $j^{\text {th }}$ floor, the axial-force capacity of the $i^{\text {th }}$ column on the $j^{\text {th }}$ floor and the number of columns on one floor respectively.

Here, the concept of the reliability of a series system (also known as the weakest link system), typified by a chain, is used to estimate the failure probability of a structure. Since the failure of any one floor constitutes the failure of the entire structure, the failure probability of a structure under rare earthquakes can be evaluated by using Equation 11:

$$
P_{f}=1-\prod_{i=1}^{M}\left(1-P^{j}\right)
$$

where $P_{f}$ and $M$ are the failure probabilities of a structure under rare earthquakes and the number of floors in

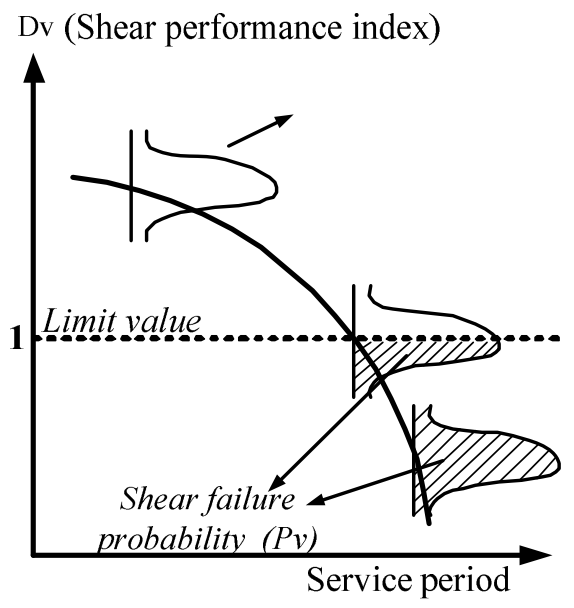

Fig. 3 Definition of shear failure probability.

the structure respectively.

The estimation method for the failure probability of a structure under rare earthquakes described above only considered the reduction of load carrying capacity due to corrosion; therefore, the deterioration risk estimated by this method tends to be conservative. In the future, the reduction of ductility due to corrosion needs to be included in this system in order for improving the accuracy of the deterioration risk.

\subsection{Serviceability performance and spalling probability}

The serviceability performance of RC structures is affected by spalling, which is caused by the formation of a crack with a width greater than $0.5-1.0 \mathrm{~mm}$ (Val and Stewart 2003). The extent of corrosion that leads to spalling can be estimated using Equations 12 and 13 (Ozaki and Morinaga):

$$
\begin{aligned}
& w_{c}=0.141 \exp (1.078 d / \phi) x \\
& r=\frac{400 w_{c}}{\rho_{s} \phi_{o}}
\end{aligned}
$$

where $w_{c}, x, d, \varphi, \varphi_{o}, \rho_{s}$, and $r$ are the corrosion of steel $\left(\mathrm{mg} / \mathrm{mm}^{2}\right)$, crack width $(\mathrm{mm})$, concrete cover $(\mathrm{mm})$, diameter of steel reinforcement $(\mathrm{mm})$, diameter of steel reinforcement before corrosion $(\mathrm{mm})$, density of steel $\left(7.85 \mathrm{mg} / \mathrm{mm}^{3}\right)$, and corrosion of steel expressed in terms of percentage weight loss (\%).

Therefore, when the extent of corrosion on the outermost reinforcing steel component in an $\mathrm{RC}$ member exceeds the crack limit concerning spalling occurrence, spalling can be assumed to occur on the surface of the concrete. As described in Section 2.1, Monte Carlo simulation was used to evaluate the spalling probability $\mathrm{P}_{\mathrm{s}}$, expressed in terms of the weighted average computed on the basis of the surface area of the members exposed to the air. However, it is reasonable to assume that chloride ingress results in a higher spalling prob- 
ability, which in turn leads to a higher probability of severe spalling or cracking during the occurrence of an occasional earthquake. This earthquake might occur occasionally in the lifetime of a structure (ISO3010, VISION2000), e.g. an earthquake with a recurrence period of 100 years in Japan or Taiwan. In this study, the product of the probability of spalling caused by chloride ingress and the annual probability of an occasional earthquake is defined as the annual probability of serviceability failure resulting from severe spalling or cracking. In addition, the mean value of the spalling probability of all the members including columns and beams is defined as the spalling probability of the structure.

\subsection{Probability-based service life assessment}

In the service life assessment method proposed in this study, a reliability function of structural safety performance, $R_{\mathrm{F}}(t)$, denoting the absence of failure of structural safety in the period $t$, was built on the basis of the hazard rate or hazard function of a deteriorating $\mathrm{RC}$ building during a rare earthquake. In the hazard rate or hazard function, the annual occurrence probability of a rare earthquake, $v_{f}$ is considered along with the failure probability of a deteriorating $\mathrm{RC}$ building under a rare earthquake:

$$
R_{F}(t)=\exp \left(-\int_{0}^{t}\left(P_{f}(t) \times v_{f}(t)\right) d t\right)
$$

Here, the acceptable reliability was set as $99.9 \%$ in determining the service life of a deteriorating RC building; in other words, failure of the building caused by rare earthquakes should not occur in its service life based on statistics. The service life estimated by this method can also be regarded as the reliable service life in terms of structural safety.

\section{Life-cycle cost and maintenance strategies}

\subsection{Life-cycle cost including deterioration risk}

The deterioration risk over a specified service period, E is estimated as follows:

$$
E=\int_{0}^{T} \frac{1}{(1+k)^{t}}\left(C_{f} P_{f} v_{f}+C_{s} P_{s} v_{s}\right) d t
$$

where $C_{f}, C_{s}, v_{f}, v_{s}, T$, and $k$ are the cost of failure, cost of severe spalling or cracking, annual probability of rare earthquakes with recurrence periods of 500 years (if a Poisson distribution is assumed, $v_{f}=0.2 \%$ ), annual probability of occasional earthquakes with recurrence periods of 100 years (if a Poisson distribution assumed, $v_{s}=1 \%$ ), specified service period (year), and discount rate respectively.

Two important conclusions can be drawn from Equation 15. Firstly, the expected cost of failure for an ultimate limit state pertains to the occurrence of an earthquake with a recurrence period of 500 years. Secondly, the expected cost of serviceability failure pertains to severe spalling or cracking caused by the occurrence of an earthquake with a recurrence period of 100 years. However, the cost of failure and the cost of severe spalling or cracking include many types of losses, e.g. function loss and injuries, which have not been discussed in this paper. According to previous studies (Kanda and Shah 1997; Stewart and Val 2003), these costs vary with the function of a structure and can be normalized by its construction cost. Based on the concept of maximum possible loss assessment, it is assumed that not only shear failure but also flexural failure can lead to a catastrophic cost. Additionally, because the cost of failure of a corroded building under earthquake conditions is considered herein, the cost associated with spalling resulting from corrosion expansion in the absence of external loads is not included in the analysis.

Besides the deterioration risk stated previously, the construction cost, retrofitting cost, and repair cost must also be considered. Therefore, the LCC, $C_{\mathrm{T}}$ is defined as follows:

$$
C_{T}=C_{I}+\sum\left(C_{\mathrm{Re} p} \frac{1}{(1+k)^{t \mathrm{R} \varphi}}\right)+\sum\left(C_{\mathrm{R} \propto} \frac{1}{(1+k)^{t \mathrm{Re}}}\right)+E
$$

where $C_{I}, C_{R e p}, C_{R e t}, t_{R e p}$, and $t_{R e t}$ are the construction cost, repair cost, retrofitting cost, time of repair (year), and time of retrofitting (year) respectively.

The reduction rate of the LCC ( $L C C R$ index, refer to Equation 17) or the minimal LCC was used to determine the optimal life-cycle maintenance strategy for $\mathrm{RC}$ structures:

$$
L C C R=\frac{N L C C-M L C C}{N L C C} \times 100 \%
$$

where $N L C C$ and $M L C C$ are the LCC when no maintenance activities are performed and the LCC when maintenance activities are performed respectively.

\subsection{Probabilistic effect assessment models for repair and retrofit}

In order to identify the suitable life-cycle maintenance strategies for an RC structure, it is necessary to specify the repair or retrofit works that can be implemented. The selected works significantly affect the lifetime performance of the RC structure. In this study, five repair or retrofit works (Table 2 and Table 3) were chosen based on the investigation results attained by other researchers and some repair or retrofit companies. Generally, steel supplementation is considered a kind of retrofit in the maintenance; therefore, TYPE-IV and TYPE-V can be regards as retrofit works in this paper, which are different from repair works, i.e. TYPE-I, TYPE-II and TYPE-III.

For improving the computing efficiency of the system used for identifying the optimal life-cycle maintenance strategy, the probabilistic effect assessment models illustrated in Fig. 4 were used to highlight the effects of 
Table 2 Practicing items in each repair or retrofit work.

\begin{tabular}{|c|l|}
\hline Repair/Retrofit technology & \multicolumn{1}{c|}{ Content } \\
\hline Finishing renewal & $\begin{array}{l}\text { The finishing of corroded RC members is renewed by using the original } \\
\text { finishing material. For this purpose, not only is the finishing recoated, but } \\
\text { also the spalling and cracking are repaired. }\end{array}$ \\
\hline Patch repair & $\begin{array}{l}\text { Patch repair including the removal of the corroded areas is performed at all } \\
\text { the areas where spalling has occurred. }\end{array}$ \\
\hline Chloride-ion removal & $\begin{array}{l}\text { The chloride ions are removed from the members entirely by means of elec- } \\
\text { trochemistry or replacement methods. }\end{array}$ \\
\hline Steel supplementation & $\begin{array}{l}\text { Based on the extent of corrosion of the outermost reinforcing steel compo- } \\
\text { nent, supplementation of the reinforcing steel is carried out. }\end{array}$ \\
\hline
\end{tabular}

Table 3 Repair or retrofit works defined in this study.

\begin{tabular}{|c|c|c|c|c|}
\hline TYPE & Finishing renewal & Patch repair & Chloride-ion removal & Steel supplementation \\
\hline TYPE-I & $\bigcirc$ & - & - & - \\
\hline TYPE-II & $\bigcirc$ & $\bigcirc$ & - & - \\
\hline TYPE-III & $\bigcirc$ & $\bigcirc$ & $\bigcirc$ & - \\
\hline TYPE-IV & $\bigcirc$ & $\bigcirc$ & - & $\bigcirc$ \\
\hline TYPE-V & $\bigcirc$ & $\bigcirc$ & $\bigcirc$ & $\bigcirc$ \\
\hline
\end{tabular}

the maintenance strategies on the failure and spalling probability directly instead of reanalyzing deterioration by using FDM, while taking into consideration the modified structural state created by the implementation of the maintenance strategies. In using these models, in addition to the deterioration proceeding from the unrepaired areas, the reoccurrence of deterioration in the repaired or retrofitted areas is also considered.

\subsubsection{TYPE-I: Finishing renewal}

For this method, the finishing of an RC member is renewed by using the original finishing material. Not only is the finishing recoated, but spalling and cracking are also repaired for this purpose. As chloride-containing corroded areas still exist after the implementation of this work, the spalling probability can be set to zero and the deterioration process of the unrepaired regions are can be estimated using Equation 18a (refer to Fig. 4a). Moreover, recurrence of deterioration in the repaired area should also be considered; the spalling probability of such areas can be estimated by using the initial construction curve without an initiation stage (refer to Fig. 4a and Equation 18b). Therefore, the spalling probabilities described above should be combined to obtain the spalling probability of members repaired by the implementation of TYPE-I (refer to Equation 18). As steel supplementation is not included in this work, failure probability is not affected by its implementation (refer to Equation 19):

\section{Spalling Probability:}

$t \leq t_{i} ; P_{i}^{s}(t)=P_{i-1}^{s}(t)$

$$
\begin{aligned}
& t>t_{i} ; \\
& \mathrm{P}_{\mathrm{i}}^{\mathrm{s}}(t)=\left(P_{i-1}^{s}(t)-P_{i-1}^{s}\left(t_{i}\right)\right)+P_{i-1}^{s}\left(t_{i}\right) \times\left(P_{o}^{s}\left(t+t_{B}-t_{i}\right)\right)(18 \mathrm{~b}
\end{aligned}
$$

Failure Probability:

$P_{i}^{f}(t)=P_{i-1}^{f}(t)$

where $P_{i-1}^{f}, P_{i}^{f}, t, t_{i}, P_{i-1}^{s}, P_{i}^{s}, P_{o}^{s}, t_{B}$ are the failure probability after the application of the $(i-1)^{t h}$ cycle of repair or retrofit $(\%)$, the failure probability after the application of the $i^{\text {th }}$ cycle of repair or retrofit (\%), the time (year), the time of application of the $i^{\text {th }}$ cycle of repair or retrofit (year), the spalling probability after the application of the $(i-1)^{t h}$ cycle of repair or retrofit $(\%)$, the failure probability after the implementation of the $i^{\text {th }}$ cycle of repair or retrofit (\%), the spalling probability when no maintenance activities are performed (\%) and the length of the initiation stage (year) respectively.

\subsubsection{TYPE-II: Finishing renewal and patch re- pair}

For this method, not only the repair activities in TYPE-I are included but also a patch repair including the removal of the corroded areas is performed at all the areas where spalling has occurred. After the implementation of this work, the spalling probability can be set to zero; the deterioration process of the unrepaired regions can be estimated using Equation 20a (refer to Fig. 4b) due to the persistence of chloride-containing corroded areas. Moreover, the recurrence of deterioration in the repaired areas should also be considered; the spalling probability of such areas can be estimated by using the initial construction curve (refer to Fig. 4b). The spalling probabilities described above should be combined to obtain 
the spalling probability of members repaired by the implementation of TYPE-II (refer to Equation 20). As steel supplementation is not included in this work, failure probability is not affected by its implementation as in the case of TYPE-I:

\section{Spalling Probability:}

$$
\begin{aligned}
& t \leq t_{i} ; P_{i}^{s}(t)=P_{i-1}^{s}(t) \\
& t>t_{i} ; \\
& \mathrm{P}_{\mathrm{i}}^{\mathrm{s}}(t)=\left(P_{i-1}^{s}(t)-P_{i-1}^{s}\left(t_{i}\right)\right)+P_{i-1}^{s}\left(t_{i}\right) \times\left(P_{o}^{s}\left(t-t_{i}\right)\right)
\end{aligned}
$$

\subsubsection{TYPE-III: Finishing renewal, patch repair, and chloride-ion removal}

For this method, all the maintenance activities included in TYPE-II are performed and the chloride ions are removed from the members entirely by means of electrochemistry or replacement methods. After the implementation of this work, the spalling probability can be set to zero ( $\mathrm{A} \rightarrow \mathrm{B}$ in Fig. 4c); the deterioration process then proceeds along the initial construction curve (refer to Equation 21). Furthermore, as the members regain their initial states, excluding the reduction in the area of the reinforcing steel, the degradation of the structural capacity of the member can be halted for a particular time period ( $C \rightarrow D$ in Fig. 4d), which corresponds to the initiation stage. Equation 22 can be used to calculate the failure probability of members repaired by the implementation of TYPE-III:

\section{Spalling Probability:}

$$
\begin{aligned}
& t \leq t_{i} ; P_{i}^{s}(t)=P_{i-1}^{s}(t) \\
& t>t_{i} ; P_{i}^{s}(t)=P_{o}^{s}\left(t-t_{i}\right)
\end{aligned}
$$

Failure Probability:

$$
\begin{aligned}
& t \leq t_{i} ; P_{i}^{f}(t)=P_{i-1}^{f}(t) \\
& t_{i}<t \leq t_{B}+t_{i} ; P_{i}^{f}(t)=P_{i-1}^{f}\left(t_{i}\right) \\
& t>t_{i}+t_{B} ; P_{i}^{f}(t)=P_{i-1}^{f}\left(t-t_{B}\right)
\end{aligned}
$$

\subsubsection{TYPE-IV: Finishing renewal, patch repair, and steel supplementation}

In this method, all the maintenance operations included in TYPE-II as well as the supplementation of the reinforcing steel (based on the extent of corrosion of the outermost reinforcing steel component) are performed. After implementing this work, spalling probability can be reset as in the case of TYPE-II, and the failure probability can be set to zero $(\mathrm{C} \rightarrow \mathrm{D}$ in Fig. $4 \mathrm{e})$; the deterio-

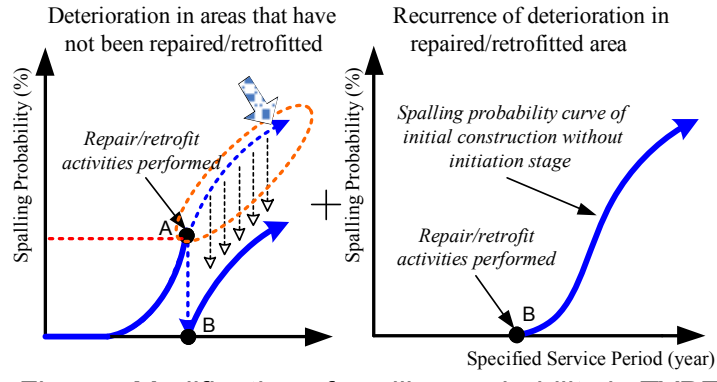

Fig. 4a. Modification of spalling probability in TYPE-I.

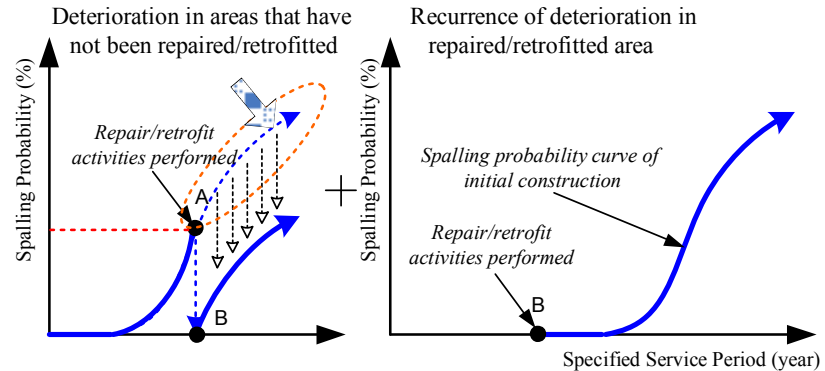

Fig. 4b. Modification of spalling probability in TYPE-II.

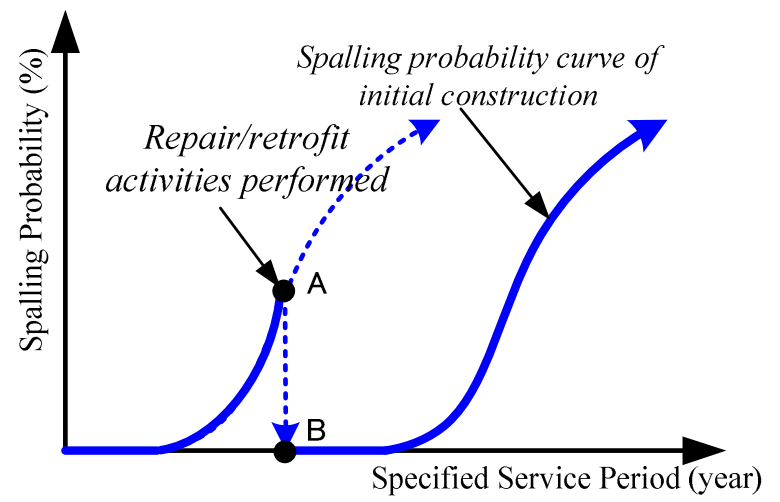

Fig. 4c Modification of spalling probability in TYPE-III.

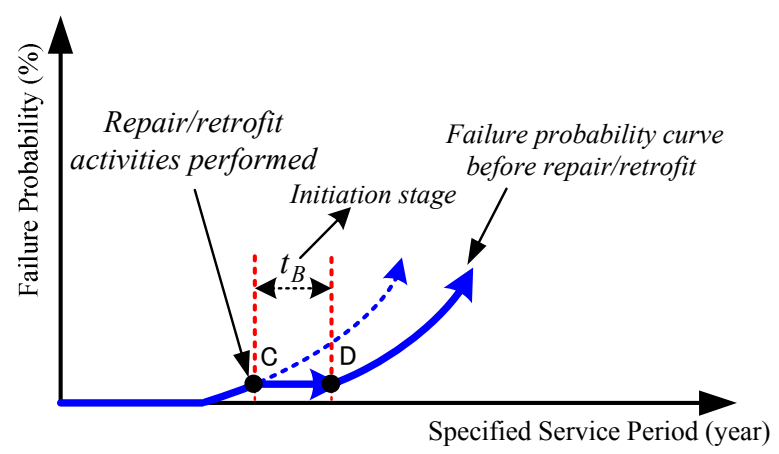

Fig. 4d Modification of failure probability in TYPE-III. 


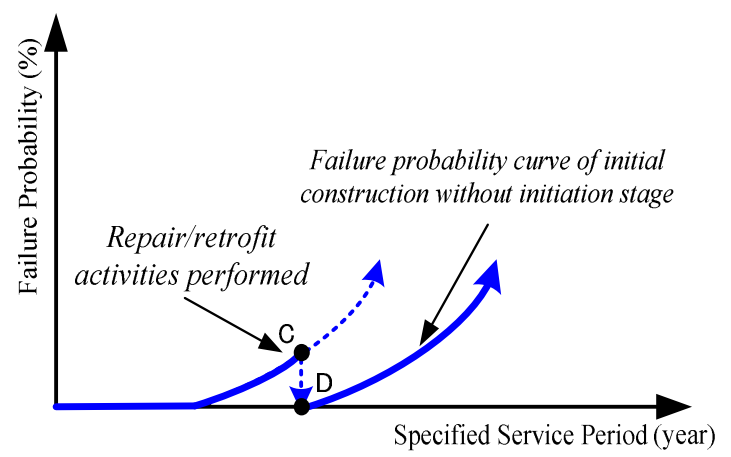

Fig. 4e Modification of failure probability in TYPE-IV.

ration process then proceeds along the initial construction curve without an initiation stage due to the persistence of chloride-containing corroded areas in the unrepaired regions. The failure probability of members repaired or retrofitted by the implementation of TYPE-IV can be calculated using Equation 23:

\section{Failure Probability:}

$$
\begin{aligned}
& t \leq t_{i} ; P_{i}^{f}(t)=P_{i-1}^{f}(t) \\
& t>t_{i} ; P_{i}^{f}(t)=P_{o}^{f}\left(t+t_{B}-t_{i}\right)
\end{aligned}
$$

where $P_{o}^{f}$ is the failure probability when no maintenance activities are performed (\%).

\subsubsection{TYPE-V: Finishing renewal, patch repair, chloride-ion removal, and steel supplementa- tion}

In addition to the maintenance operations included in TYPE-III, based on the extent of corrosion of the outermost reinforcing steel component, supplementation of the reinforcing steel is carried out in TYPE-V. After the implementation of this work, the members regain their initial states entirely, and the spalling probability and failure probability can be set to zero $(\mathrm{A} \rightarrow \mathrm{B}$ in Fig. 4c; $\mathrm{C} \rightarrow \mathrm{D}$ in Fig. 4f); the deterioration process then proceeds along the initial construction curve. The spalling probability and failure probability of members repaired using this work can be estimated using Equations 21 and 24 respectively:

\section{Failure Probability:}

$$
\begin{aligned}
& t \leq t_{i} ; P_{i}^{f}(t)=P_{i-1}^{f}(t) \\
& t>t_{i} ; P_{i}^{f}(t)=P_{o}^{f}\left(t-t_{i}\right)
\end{aligned}
$$

The five repair or retrofit techniques described herein can be applied to members, and the spalling and failure probability of the entire structure can be estimated using the methods described in Sections 3.2 and 3.3.

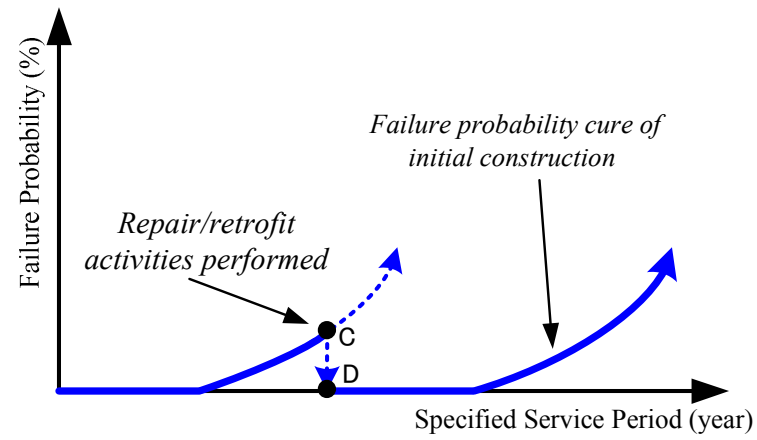

Fig. $4 \mathrm{f}$ Modification of failure probability in TYPE-V.

\section{Cost evaluation for repair or retrofit works}

In order to enhance the estimation accuracy of the LCC of a structure, a cost evaluation method based on the assessment of practical repair or retrofit works should be developed. The repairing or retrofitting costs should include not only the unit prices of the repairing or retrofitting works but also account for the expected extent of repair or retrofit. The unit prices of the repairing or retrofitting works included in each strategy can be compared against the historical cost data, but appropriate methods are not available for evaluating the expected extent of the maintenance activities. Therefore, in this study, a method for evaluating the cost of repair or retrofit is proposed; this method utilizes the deterioration degree defined by the spalling probability (refer to Table 4), with the spalling probability limited to an allowable value. It is reasonable to assume that the repair or retrofit works included in each strategy will change if the deterioration degree changes and that the spalling probability of concrete cover can be used to estimate the rate of repair area in an RC member. Using two allowable deterioration degrees, i.e. 15\% (Light, Level I) and 30\% (Medium, Level II), and the equations listed in Table 5, which were obtained from Kim et al. (2007), the repair and retrofit costs normalized by the cost of initial construction were evaluated herein. In addition, considering the use of a targeted building, the allowable deterioration degree can be decided by its owner or user.

Table 4 Degree of deterioration corresponding to the spalling probability.

\begin{tabular}{|c|c|}
\hline $\begin{array}{c}\text { Spalling Probability } \\
(\%)\end{array}$ & Deterioration Degree \\
\hline $0 \leqq P_{\mathrm{S}}<3$ & None or Little \\
\hline $3 \leqq P_{\mathrm{S}}<15$ & Light \\
\hline $15 \leqq P_{\mathrm{S}}<50$ & Medium \\
\hline $50 \leqq P_{\mathrm{S}}<85$ & Heavy \\
\hline $85 \leqq P_{\mathrm{S}}<100$ & Serious (deteriorated entirely) \\
\hline
\end{tabular}




\section{Case study}

The applicability of the method proposed in this study was investigated by using it to analyze the LCC of a twelve-story RC building (frame structure, refer to Fig. 5). The parameters required for the analysis of deterioration are listed in Table 6 and those required for computing the LCC are listed in Table 5. Using the service

Table 5 Parameters for the estimation of LCC.

\begin{tabular}{|c|c|c|}
\hline \multicolumn{2}{|c|}{ Construction cost $\left(C_{\mathrm{I}}\right)$} & 1.00 \\
\hline \multicolumn{2}{|c|}{$\begin{array}{l}\text { Cost corresponding to failure }\left(C_{\mathrm{f}}\right) \\
\text { (Kanda et al. 1997) }\end{array}$} & 10.0 \\
\hline \multicolumn{2}{|c|}{$\begin{array}{c}\text { Cost corresponding to severe } \\
\text { spalling/cracking }\left(C_{\mathrm{s}}\right) \\
\text { (Stewart et al. } 2003)\end{array}$} & 2.00 \\
\hline \multicolumn{2}{|c|}{ Discount rate $(k)$} & $1.00 \%$ \\
\hline \multirow{2}{*}{$\begin{array}{c}\text { Cost corresponding to } \\
\text { TYPE-I }\end{array}$} & $P_{\mathrm{sw}}=15 \%$ & 0.035 \\
\hline & $P_{\mathrm{sW}}=30 \%$ & 0.041 \\
\hline \multirow{2}{*}{$\begin{array}{c}\text { Cost corresponding to } \\
\text { TYPE-II }\end{array}$} & $P_{\mathrm{sw}}=15 \%$ & 0.037 \\
\hline & $P_{\mathrm{sw}}=30 \%$ & 0.044 \\
\hline \multirow{2}{*}{$\begin{array}{c}\text { Cost corresponding to } \\
\text { TYPE-III }\end{array}$} & $P_{\mathrm{sw}}=15 \%$ & 0.066 \\
\hline & $P_{\mathrm{sW}}=30 \%$ & 0.068 \\
\hline \multirow{2}{*}{$\begin{array}{l}\text { Cost corresponding to } \\
\text { TYPE-IV }\end{array}$} & $P_{\mathrm{sW}}=15 \%$ & $(0.037+0.2 r)$ \\
\hline & $P_{\mathrm{sW}}=30 \%$ & $(0.044+0.2 r)$ \\
\hline \multirow{2}{*}{$\begin{array}{c}\text { Cost corresponding to } \\
\text { TYPE-V }\end{array}$} & $P_{\mathrm{sw}}=15 \%$ & $(0.066+0.2 r)$ \\
\hline & $P_{\mathrm{sw}}=30 \%$ & $(0.068+0.2 r)$ \\
\hline
\end{tabular}

$* \mathrm{P}_{\mathrm{sw}}$ : Allowable deterioration or spalling degree of the concrete cover

* r: Corrosion of steel expressed as percentage weight loss $(\%)$

Table 6 Parameters for the estimation of deterioration.

\begin{tabular}{|c|c|}
\hline Compression strength of concrete & $45.0 \mathrm{~N} / \mathrm{mm}^{2}$ \\
\hline Water-cement ratio $(\mathrm{W} / \mathrm{C})$ & $55 \%$ \\
\hline Tensile reinforcement ratio & $2.5 \%$ \\
\hline Apparent diffusion coefficient $\left(D_{\mathrm{p}}\right)$ & $1.91 \mathrm{~cm}^{2} /$ year \\
\hline Initial chloride content in concrete $\left(C_{\text {init }}\right)$ & $0.0 \mathrm{~kg} / \mathrm{m}^{3}$ \\
\hline Surface chloride content $\left(C_{\mathrm{o}}\right)$ & $3.0,6.0,9.0 \mathrm{~kg} / \mathrm{m}^{3}$ \\
\hline
\end{tabular}

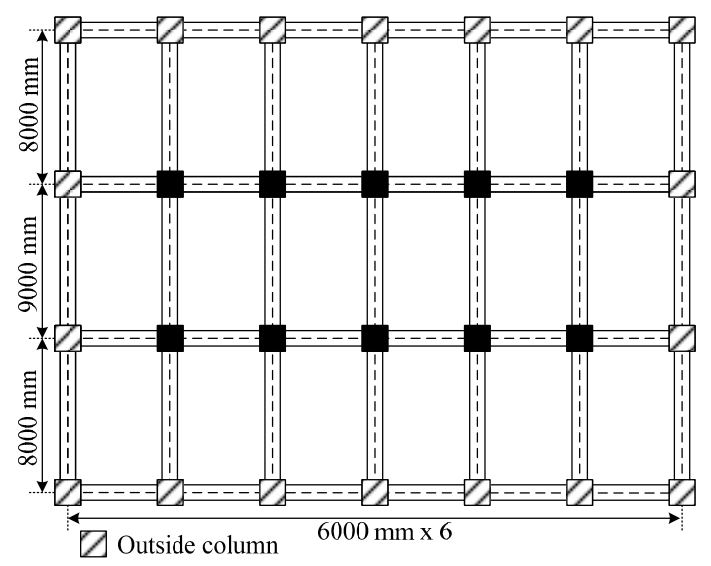

Fig. 5 Floor plan of the RC building. life assessment method proposed herein, the results are obtained and shown in Fig. 7. When the allowable reliability is set to be $99.9 \%$, the reliable service lives under different surface chloride contents are about 37, 22 and 16 years, respectively. It was found that maintenance activities were needed to prolong their service lives to 100 years for all cases.

In addition to selecting the maintenance works to be used, the time taken for which repair or retrofit activities are performed, which depends on the allowable degree of concrete spalling, should be set. Two allowable degrees of spalling, i.e. 15\% (Level I) and 30\% (Level II), were chosen in order to identify the optimal life-cycle maintenance strategy consisting of only one type of re-

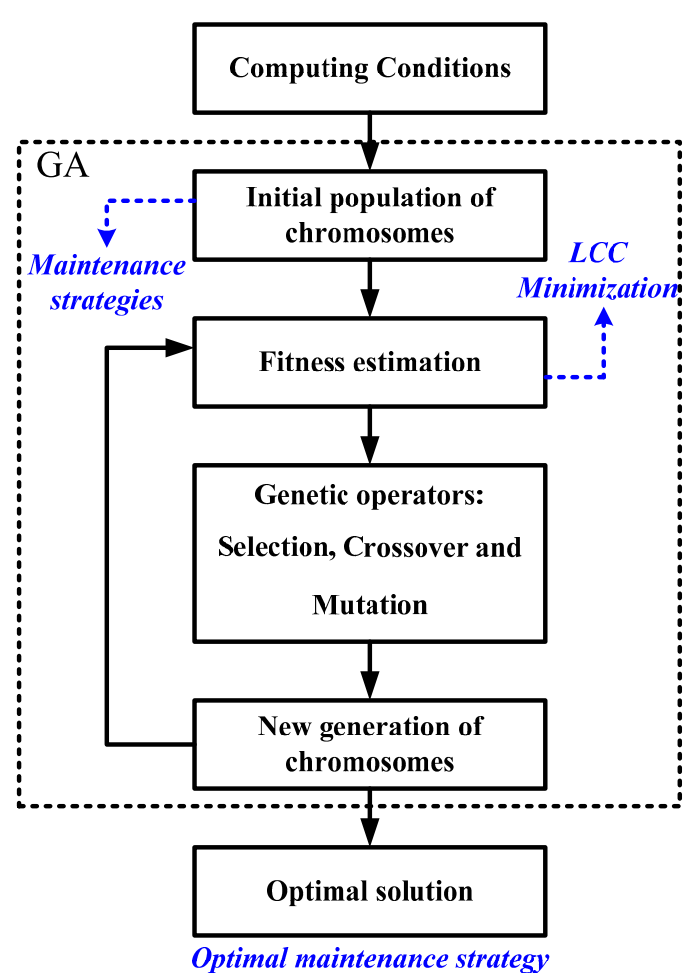

Fig. 6 Flowchart of the GA computing procedure.

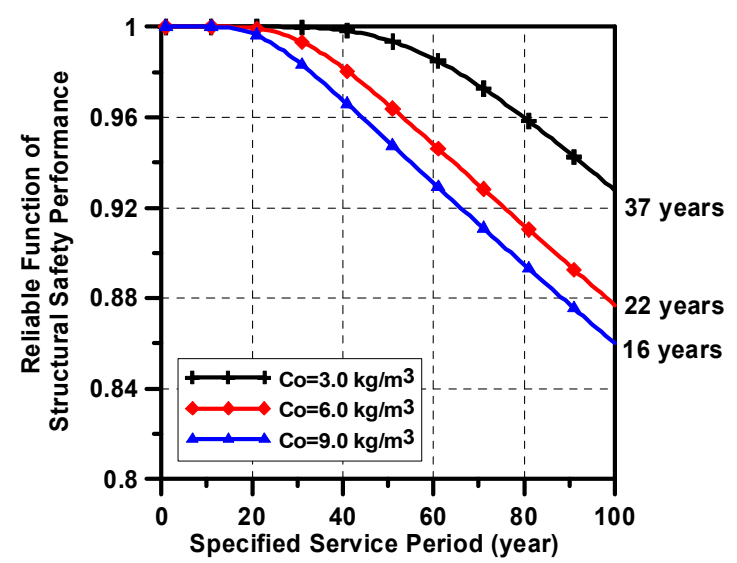

Fig. 7 Reliable function of structural safety performance. 
pair or retrofit; the results obtained by implementing each maintenance strategy are shown in Figs. 8, 9, and 10. Besides, a genetic algorithm (GA) evaluation function was used to find the minimal LCC. The problem (fitness) and the answer (chromosome) were defined as the LCC minimization and the maintenance plan that consists of random types of repair or retrofit respectively. The GA computing procedure is illustrated by the flowchart shown in Fig. 6 (Chiu and Chien 2003). In other words, three maintenance scenarios (refer to Table 7) were defined to search for the optimal maintenance strategy for this case.

Figure 8 shows that when the specified service period is set to a value greater than 60 years and when the surface chloride content is $3.0 \mathrm{~kg} / \mathrm{m}^{3}$, although the maintenance cost associated with the implementation of TYPE-V is higher than that of other cases, the summation of the maintenance cost and the deterioration risk associated with the implementation of TYPE-V is lower than that of all other cases, irrespective of whether the Level-I or Level-II limit is used. Therefore, in order to prolong the service life of an RC structure subjected to chloride ingress, TYPE-V, which includes finishing renewal, patch repair, chloride-ion removal, and steel supplementation, is the most effective maintenance strategy in terms of the minimal LCC. In addition, the surface chloride contents of $6.0 \mathrm{~kg} / \mathrm{m}^{3}$ and $9.0 \mathrm{~kg} / \mathrm{m}^{3}$ produced similar results, as illustrated in Figs. 9 and $\mathbf{1 0 .}$

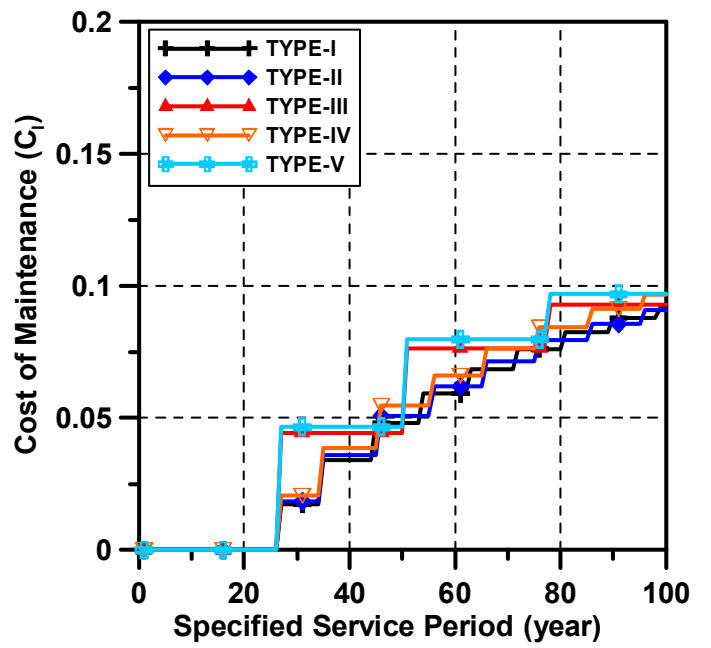

a. Cost of maintenance associated with Level I.

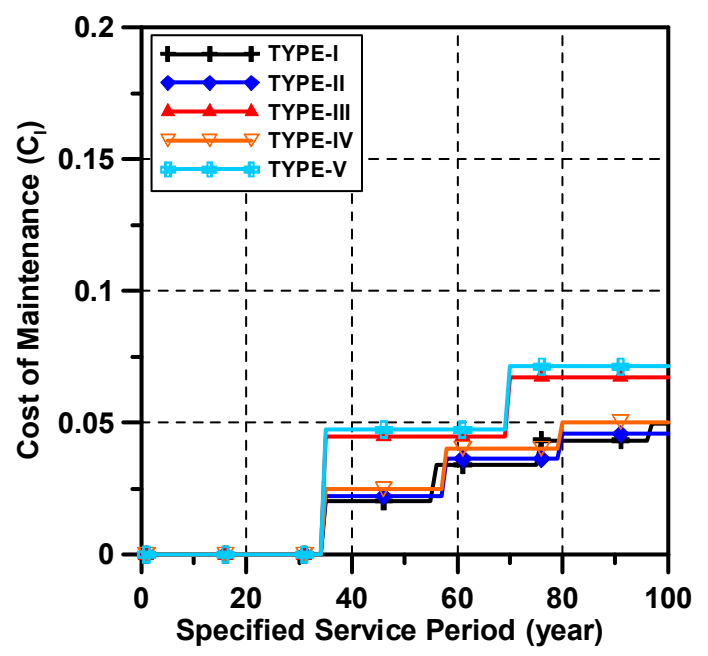

c. Cost of maintenance associated with Level II.

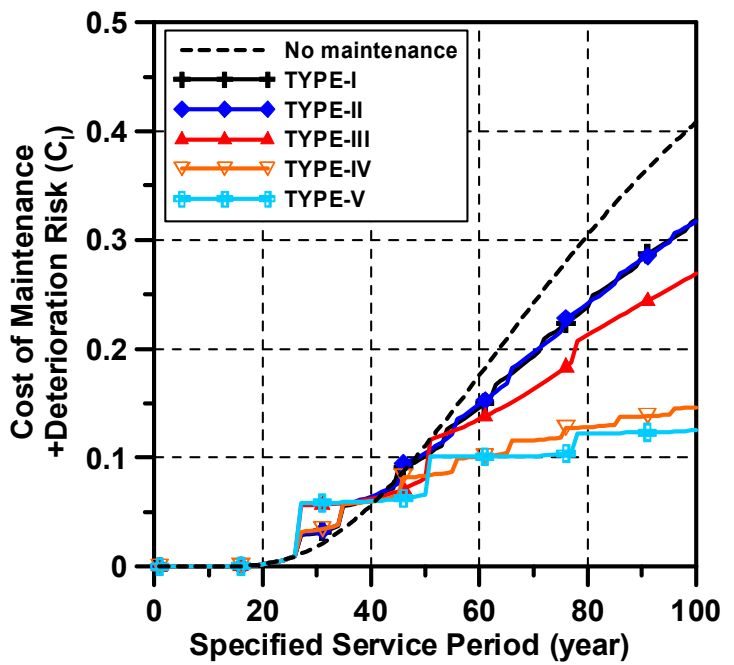

b. Cost of maintenance and deterioration risk associated with Level I.

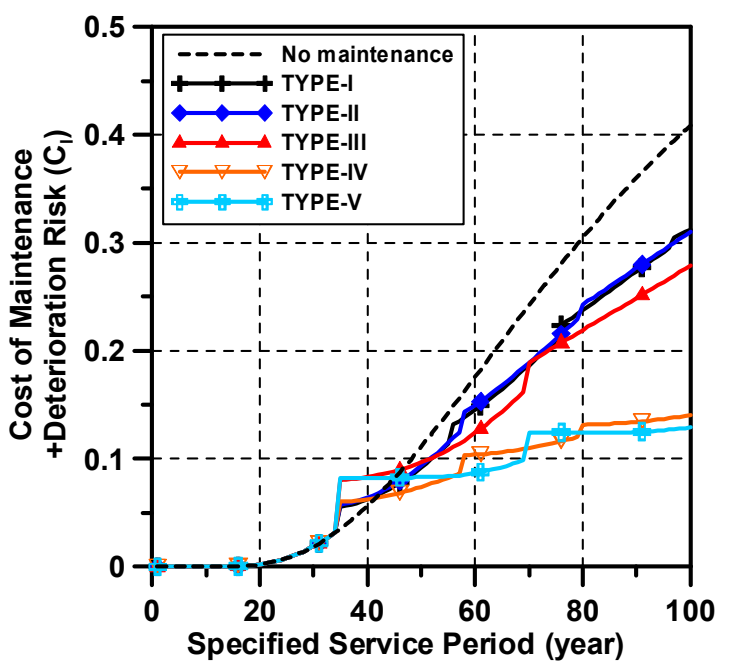

d. Cost of maintenance and deterioration risk associated with Level II.

Fig. 8 Surface chloride content $\left(C_{o}\right): 3.0 \mathrm{~kg} / \mathrm{m}^{3}$. 


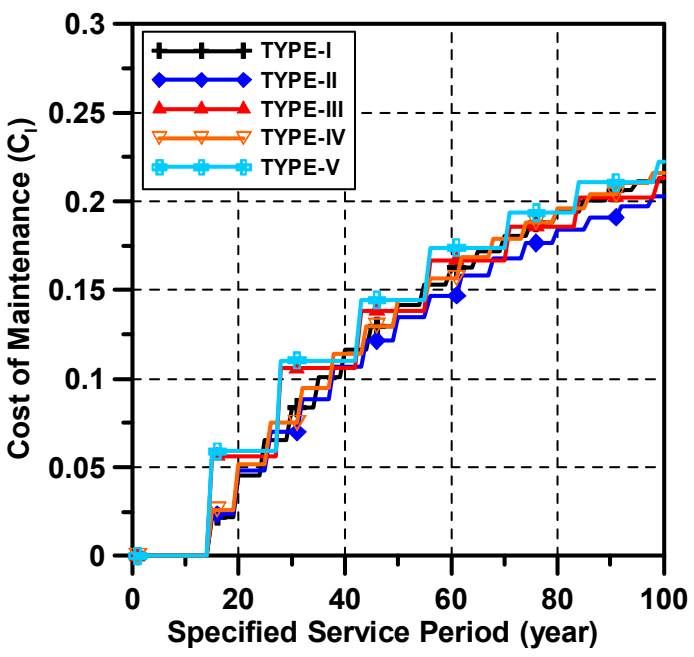

a. Cost of maintenance associated with Level I.

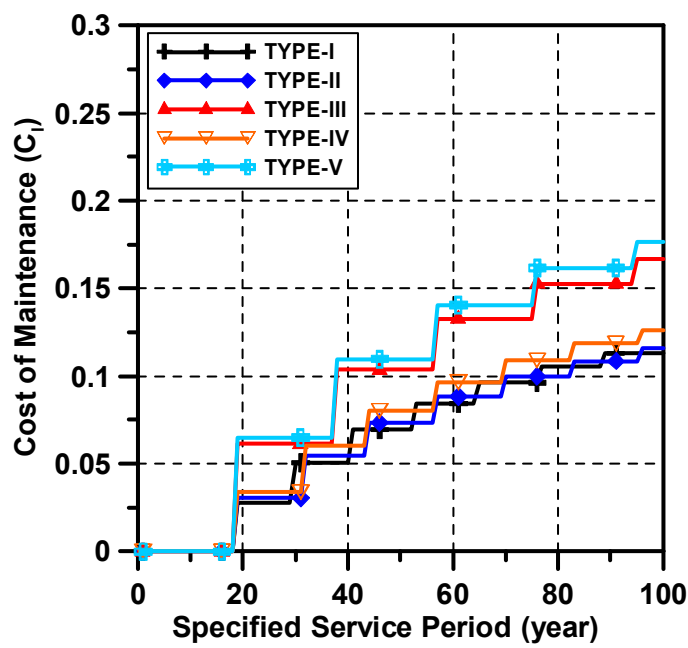

c. Cost of maintenance associated with Level II.

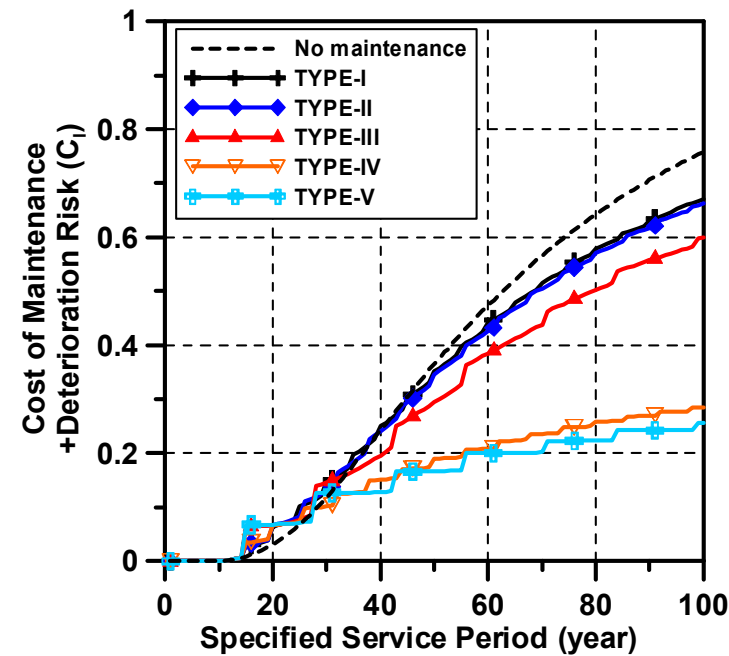

b. Cost of maintenance and deterioration risk associated with Level I.

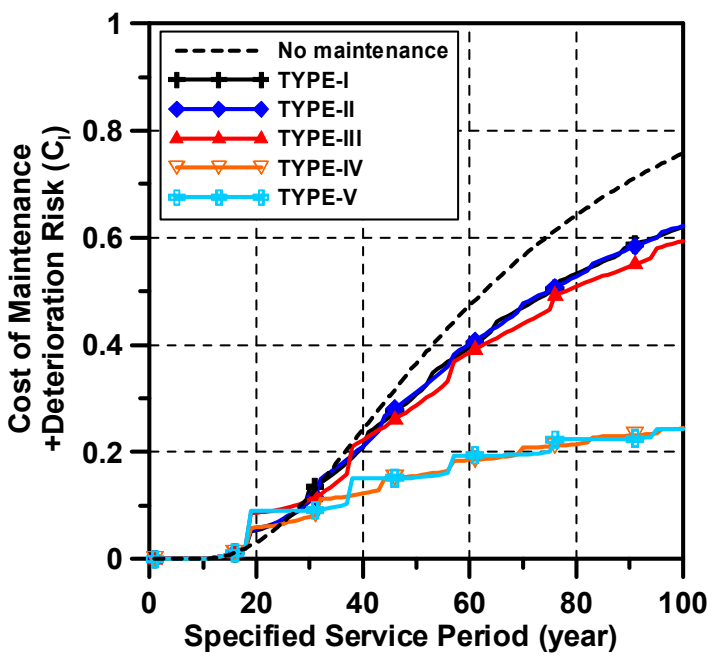

d. Cost of maintenance and deterioration risk associated with Level II.

Fig. 9 Surface chloride content $\left(C_{0}\right): 6.0 \mathrm{~kg} / \mathrm{m}^{3}$.

Table 8 LCC when Level I is used (Scenario A, Specified service time: 100 years).

\begin{tabular}{|c|c|c|c|c|c|c|c|}
\hline \multirow{2}{*}{$\begin{array}{c}\text { Surface chloride } \\
\text { content }\left(\mathrm{kg} / \mathrm{m}^{3}\right)\end{array}$} & \multicolumn{2}{|c|}{ No maintenance } & \multirow{2}{*}{ TYPE-I } & \multirow{2}{*}{ TYPE-II } & \multirow{2}{*}{ TYPE-III } & \multirow{2}{*}{ TYPE-IV } & TYPE-V \\
\cline { 2 - 6 }$n$ & LCC & Risk & & 1.32 & 1.27 & 1.15 & $1.13^{*}$ \\
\hline 3.0 & 1.41 & $0.41(41 \%)$ & 1.32 & 1.66 & 1.60 & 1.28 & 1.26 \\
\hline 6.0 & 1.76 & $0.76(76 \%)$ & 1.67 & 1.88 & 1.81 & 1.41 & 1.35 \\
\hline 9.0 & 1.92 & $0.92(92 \%)$ & 1.88 & &
\end{tabular}

* Optimal maintenance strategy

When a specified service period of 100 years was set, the building has a minimal LCC when the Level-II limit and TYPE-IV in Scenario B were used according to Tables 8 and 9. Although the optimal maintenance strategies obtained by Scenarios B and C (refer to Table 10) are different, their LCCs are almost identical. In addition, the fact that Scenario B with only one repair or retrofit operation is easier to be arranged in maintenance activities than Scenario $\mathrm{C}$ is reasonable. The results re- vealed that the optimal maintenance strategies - those including steel supplementation, are effective in reducing the LCCs of RC structures located in regions with a high risk of chloride ingress and seismic activity; the rates of deterioration risk in the LCCs are reduced to below 12\% from $40-50 \%$ as shown in Fig. 11. For example, when the surface chloride concentration is set to be $9.0 \mathrm{~kg} / \mathrm{m}^{3}$, the rates of cost caused by the severe spalling/cracking under occasional earthquakes and cost 


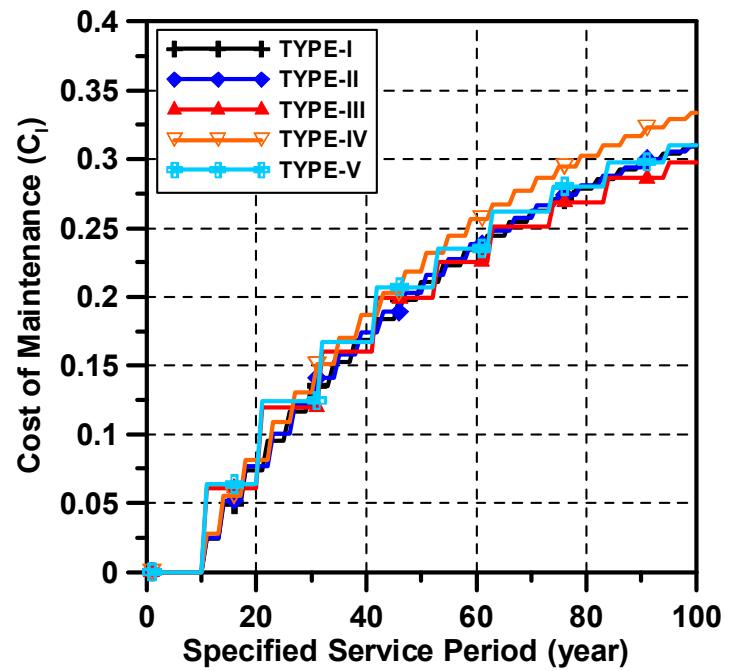

a. Cost of maintenance associated with Level I.

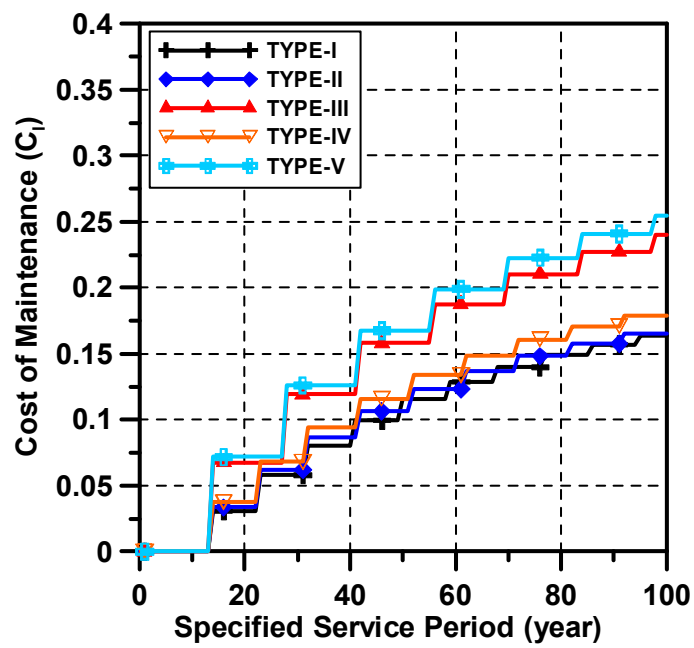

c. Cost of maintenance associated with Level II.

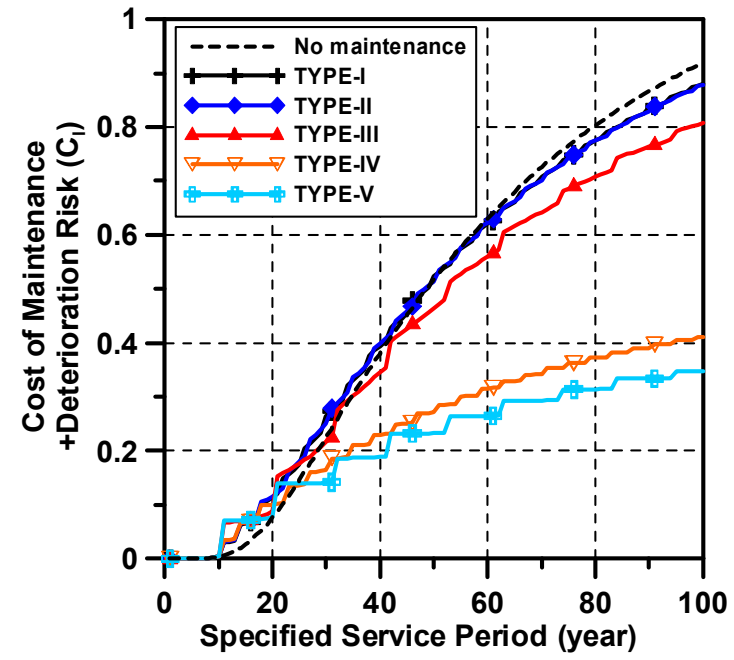

b. Cost of maintenance and deterioration risk associated with Level I.

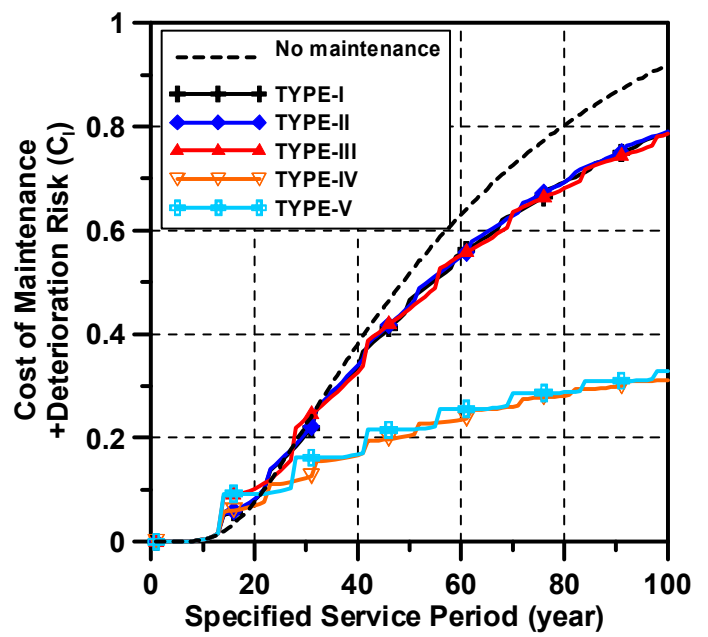

d. Cost of maintenance and deterioration risk associated with Level II.

Fig. 10 Surface chloride content $\left(C_{0}\right): 9.0 \mathrm{~kg} / \mathrm{m}^{3}$.

Table 9 LCC when Level II is used (Scenario B, Specified service time: 100 years).

\begin{tabular}{|c|c|c|c|c|c|c|c|}
\hline \multirow{2}{*}{$\begin{array}{c}\text { Surface chloride } \\
\text { content }\left(\mathrm{kg} / \mathrm{m}^{3}\right)\end{array}$} & \multicolumn{2}{|c|}{ No maintenance } & \multirow{2}{*}{ TYPE-I } & \multirow{2}{*}{ TYPE-II } & \multirow{2}{*}{ TYPE-III } & \multirow{2}{*}{ TYPE-IV } & \multirow{2}{*}{ TYPE-V } \\
\cline { 2 - 7 } & LCC & Risk & & 1.31 & 1.28 & 1.14 & $1.13^{*}$ \\
\hline 3.0 & 1.41 & $0.41(41 \%)$ & 1.31 & 1.62 & 1.59 & $1.24^{*}$ & $1.24^{*}$ \\
\hline 6.0 & 1.76 & $0.76(76 \%)$ & 1.62 & 1.79 & 1.79 & $1.31^{*}$ & 1.33 \\
\hline 9.0 & 1.92 & $0.92(92 \%)$ & 1.79 & &
\end{tabular}

*Optimal maintenance strategy

Table 10 Minimal LCC obtained by GA (Scenario C).

\begin{tabular}{|c|c|c|}
\hline Surface chloride content $\left(\mathrm{kg} / \mathrm{m}^{3}\right)$ & LCC & \multicolumn{1}{|c|}{ Optimal Maintenance Strategy (years-TYPE) } \\
\hline 3.0 & 1.12 & 24-V, 40-III, 50-V, 74-V \\
\hline 6.0 & 1.23 & $15-\mathrm{V}, 23-\mathrm{III}, 35-\mathrm{IV}, 51-\mathrm{V}, 67-\mathrm{V}, 75-\mathrm{III}$, 87-IV \\
\hline 9.0 & 1.31 & 14-IV, 26-IV, 38-IV, 50-IV, 62-IV, 74-IV, 88-IV \\
\hline
\end{tabular}

caused by failure under rare earthquakes in the LCC are reduced from $26 \%$ and $21.9 \%$ to $0.5 \%$ and $11.5 \%$ by the optimal maintenance strategy (the rate of cost of maintenance in the LCC is $11.8 \%$ ), respectively. In Fig. 12, it is clear that the service life can be prolonged when the optimal maintenance strategy is implemented.

In summary, repair strategy TYPE-IV, TYPE-V and an allowable deterioration degree corresponding to 


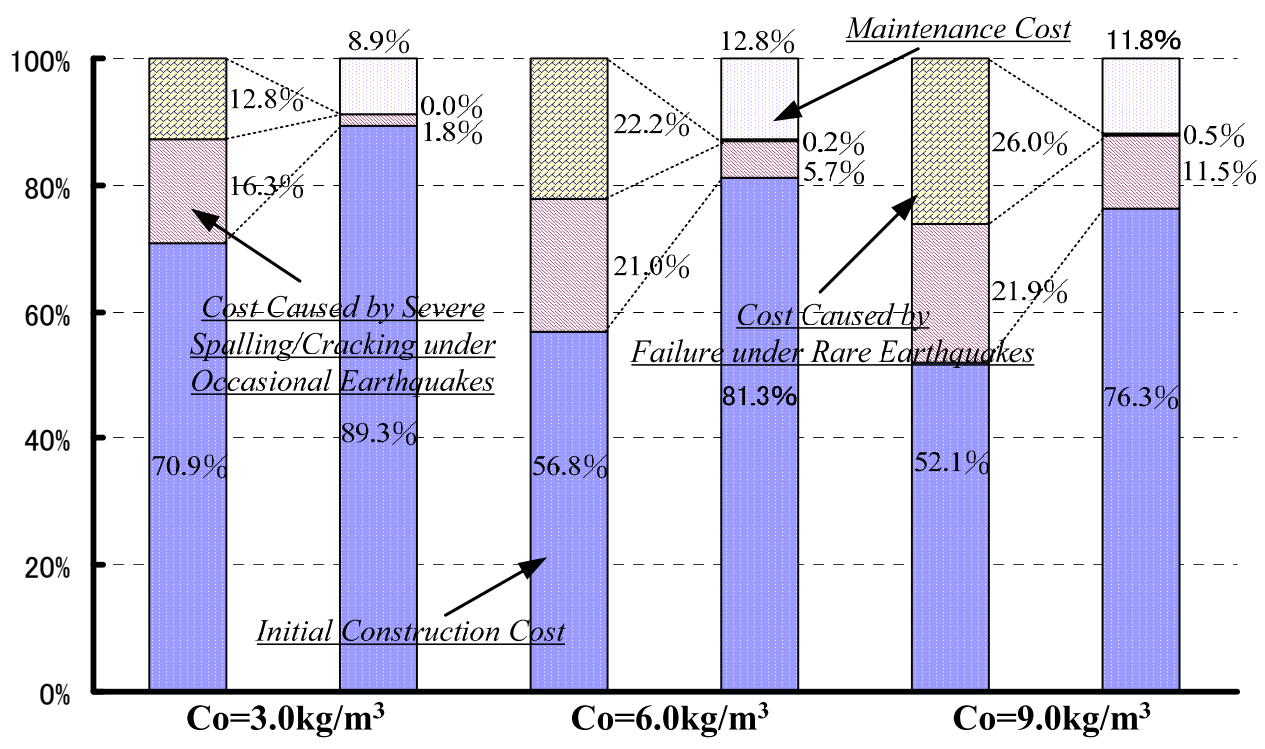

Fig. 11 Rates of each cost in the LCCs.

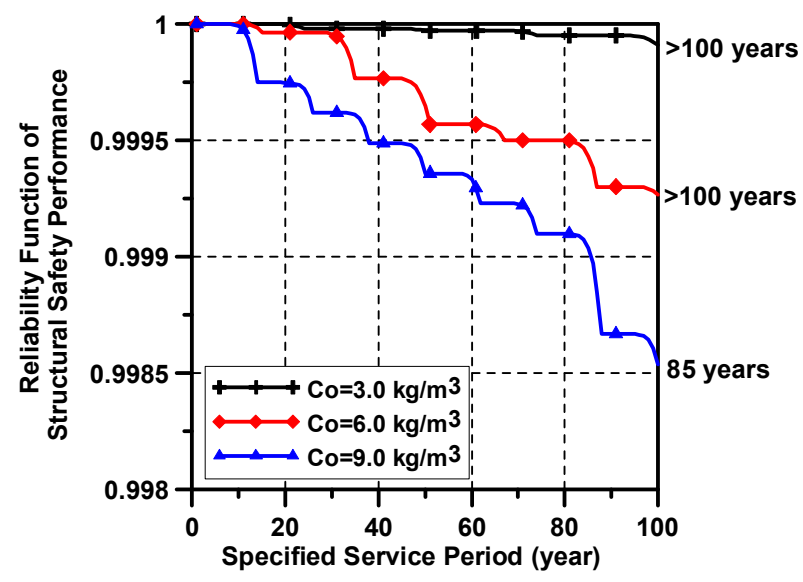

Fig. 12 Reliable function of structural safety performance when the optimal maintenance strategy is implemented.

Level-II (Scenario B) are recommended to maintain the twelve-story building over the specified service period of 100 years. This conclusion was made on the basis of the obtained LCCR index or minimal LCC. Moreover, after the optimal maintenance strategy is implemented in each case, the service life is prolonged to over 100 years except for the case where the surface chloride content is $9.0 \mathrm{~kg} / \mathrm{m}^{3}$. This means that for the case where the surface chloride content is $9.0 \mathrm{~kg} / \mathrm{m}^{3}$, not only the maintenance works proposed in this study but also finishing materials that can suppress chloride diffusion are needed.

\section{Conclusion}

In this paper, we described a system that can be used to estimate the deterioration risk induced by chloride ingress resulting from failure and severe spalling or cracking during earthquakes. In addition, five repair or retrofit techniques were considered and their probabilistic models were developed in this study to investigate the effect of each strategy. Besides the values of minimal LCC including the deterioration risk, we also used the values of LCCR index to identify the optimal maintenance strategy for RC buildings; case studies were used to demonstrate the applicability of the system. The results revealed that maintenance strategies that include steel supplementation, i.e. TYPE-IV and TYPE-V as described in this paper, are effective in reducing the LCC of RC buildings located in regions with high hazard of chloride ingress and seismic activity, e.g. Japan and Taiwan.

Although specific recurrence periods of earthquakes were considered in this study, other values can be chosen in accordance with the selected seismic design codes. In the future, instead of using specific recurrence periods of earthquakes, seismic hazard analysis will be incorporated in this system in order to develop more useful estimation models.

\section{References}

AIJ (1988). "Design guideline for earthquake resistant reinforced concrete buildings based on ultimate strength concept." Tokyo: Architectural Institute of Japan. (in Japanese)

AIJ (2004). "Recommendations for durability design and construction practice of reinforced concrete." Tokyo: Architectural Institute of Japan. (in Japanese)

Chiu, C. K., Noguchi, T. and Kanematsu, M. (2008). "Optimal maintenance plan for RC members by minimizing life-cycle cost including deterioration risk due to carbonation." Journal of Advanced Concrete Technology, 6(3), 469-480.

Chiu, C. K. and Chien, W. Y. (2009). "Risk-based life-cycle maintenance strategies for chloride-attacked 
$\mathrm{RC}$ buildings located in the region with high seismic hazard." International Conference in Commemoration of the 10th Anniversary of the 1999 Chi-Chi Earthquake, Taiwan.

Frangopol, D. M., Lin, K. Y. and Estes, A. C. (1997). "Life-cycle cost design of deteriorating structures." Journal of Structure Engineering (ASCE), 123(10), 286-297.

JCI (1998). "Committee report of study on the rehabilitation of concrete structures." Tokyo: Japan Concrete Institute. (in Japanese)

JCI (2004). "Committee report of estimation models for long-term performance of concrete structures." Tokyo: Japan Concrete Institute. (in Japanese)

Kato, Y. and Uomoto, T. (2005). "Proposal for quantitative evaluation methodology of inspection value in maintenance of concrete structures based on repair-risk." Journal of Advanced Concrete Technology, 3(3), 363-370.

Kanda, J. and Shah, H. (1997). "Engineering role in failure cost evaluation for buildings." Structure Safety, 19(1), 79-90.

Kim, T., Kinugasa, H. and Koga, K. (2007). "Repair plan for RC structure from economic point of view of durability deterioration." Proceedings of the Japan Concrete Institute, 29(1), 843-848. (in Japanese)

Kanematsu, M. and Noguchi, T. (2001). "Study on optimization method of maintenance and repair scheme by applying a genetic algorithm." Proceedings of JCI Symposium on Evaluation and Maintenance Planning for Combined Deterioration of
Concrete Structures, 51-54. (in Japanese)

Mori, Y. and Ellingwood, B. R. (1994). "Maintaining reliability of concrete structures. II: Optimum inspection/repair." Journal of Structure Engineering (ASCE), 120(3), 846-862.

Ozaki, T. and Morikawa, H. (2005). "Performance evaluation of $\mathrm{RC}$ bridges with corroded reinforcing bars based on condition rating method." Proceedings of the Japan Concrete Institute, 27(2), 1573-1578. (in Japanese)

Sancharoen, P., Kato, and Y., Uomoto, T. (2008). "Probability-based maintenance planning for RC structures attacked by chloride." Journal of Advanced Concrete Technology, 6(3), 481-495.

Stewart, M. G. and Val, D. V. (2003). "Multiple limit states and expected failure costs for deteriorating reinforced concrete bridges." Journal of Bridge Engineering (ASCE), 8(6), 405-415.

Takahashi, T., Sakai, M., Seki, H. and Matsushima, M. (2005). "Calculation of LCC and selection system of repairing method for reinforced concrete members exposed to sea environments." Concrete Research and Technology (JCI), 16(3), 21-29. (in Japanese)

Val, D. V. and Stewart, M. G. (2003). "Life-cycle cost analysis of reinforced concrete structures in marine environments." Structure Safety, 25, 343-362.

Val, D. V. (2005). "Effect of different limit states on life-cycle cost of RC structures in corrosive environment." Journal of Infrastructure Systems (ASCE), 11(4), 231-240. 